Jean-Paul Daoust est né le 30 janvier 1946 à Valleyfield, Québec. Il a terminé un B.A. et une Maîtrise en lettres à l'Université de Montréal. Il est présentement en rédaction de thèse de doctorat à l'Université de Sherbrooke, et est professeur au cégep Edouard-Montpetit. Il a collaboré à une cinquantaine de revues dont HobolQuébec, Jeu, Lèvres Urbaines, NBJ, Trois, Moebius, Eloizes (Acadie), Rampike (Toronto), Jungle (France). II a fait de nombreuses lectures de ses poèmes à plusieurs endroits et dans certains festivals dont Place aux Poètes, La nuit de la poésie, Festival "Hors-Jeu" au musée d'art contemporain, Le Festival International de Poésie de TroisRivières, La Rencontre des Poètes d'origine latine (Mexico, 1987), La Semaine de Poésie Québécoise à Epernay (France, 1986). Il a participé également à la semaine d'activités culturelles dans le cadre des jeux olympiques de Calgary (février 1988). Il a publié depuis 1976 une douzaine d'ouvrages de poésie, et un roman. Il fait aussi partie du comité de direction de la revue de poésie ESTUAIRE.

\title{
Oeuvres:
}

Oui, cher, récit (Montréal: Cul Q. 1976); Chaises longues, livre-objet (Montréal, Cul Q. 1977); Portrait d'intérieur, poésie (Trois-Rivières: APLM, 1981); Poèmes de Babylone, poésie (TroisRivières: Ecrits des Forges, 1982); Black Diva, poésie (Montréal: Lèvres Urbaines, 1983); Soleils d'Acajou, roman (Montréal: Nouvelle Optique, 1983); Taxi, poésie (Trois-Rivières: Ecrits des Forges, 1984); Dimanche après-midi, poésie (Trois-Rivières: Ecrits des Forges, 1985); La peau du coeur et son opéra, poésie (Saint-Lambert: le Noroît, 1985); Les garçons magiques, poésie (Montréal: VLB, 1986); Du dandysme, poésie (Montréal: NBJ, 1986); Suite contemporaine, poésie (Trois-Rivières: Ecrits des Forges, 1987); Les cendres belues, poésie (Trois-Rivières: Ecrits des Forges, 1990).

\section{Les Poses de la lumière}

Au milieu du fatras des mondanités

Où la lumière des lustres arrache aux yeux

Des poèmes parnassiens à la démesure des dandys

Les sentiments guillotiné sont des diamants

Que les annulaires portent en guise de deuil 


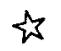

Ecrire au futur antérieur une vie présente

Faite d'anathèmes de joies d'espoirs

Oser s'agenouiller au creux d' un lit

Saisir la démesure de son extase

L'embrasser encore et encore

Dans la détresse des soirs rêver l'autre

Systèmes d'alarme dans les rues en quête

La pire des tortures est-ce la solitude

Le taxi passe voilà le corps dit la morgue

Les fêtes sont-elles devenues si impossibles

$$
\{
$$

Le sexe est un songe prêté par les anges

On leur enleve volontiers nos desseins

On écrit leur réconfort imaginé éternel

Les miroirs faussent nos gestes

Comment vérifier ce que savent les yeux

Assis dans le décalage des fusées on s'estompe

Mes yeux scrutent la puissance du noir

Les volcans suspendus dans l'amiante des lunes

Où les lumières sont des souris qui grignotent

Ouvertement des souvenirs confidentiels

$$
\text { s }
$$

Il faut bien boire pour se déraciner

Aux torpeurs des draps vides

A l'amalgame des connaissances 
Au retour des magies stupéfiantes

Dans l'alcool la vie fleurit la nuit<smiles>[3H]</smiles>

Le sentiment abscon de toute fin

De tout visa du corps étranger

A même le territoire qu'on dit civilisé

La lumière défunte on espère encore

Comme pour les histoires d'amour

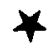

Je connais les mots de la folie

Ils sont ronds et font peur

Des cris qui ravissent

Quand ils apparaissent il faut les ignorer

Malgré leurs charmes

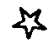

Je les regarde ces pétales d'avril

Une teinture dans l'air fatigué d'hiver

Tout est prêt tout semble si vide

Un cirque à recommencer encore

Je les regarde en état d'hébétude

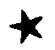

Tu me nourris de tant de signes

A l'aise avec l'apesanteur

L'âme dans ses projets en faillite

Redevient analphabète se faufile

Troglodyte dans les cavemes des étoiles 


$$
3
$$

Dans la lumière des passages enregistrés

Ici les blessures ne se ferment plus

Malgré les vagues malgré nos amours

$S$ 'enfoncer dans les canyons neutres

Tu me tends une main à bout de souffle

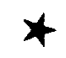

Certains pores sont des opales

Ceux qu'on lèche fascines

Les combats des hésitations

La fievre d'aimer des pêcheurs de corail

Nous finirons tous par en mourir

$$
\text { s }
$$

Les miroirs montrent les vies

Les réussies qu'on préfère voir

Les idées en banqueroute dérangent

Celles qu'on croyait si nobles

Mais entre nos bras nous découvrir si beaux

Continuer d'un château à l'autre

Image sympathique d'un symbole désuet

Tu me retrouves pour unir nos gestes

Pour faire quand nous nous renversons

Les chutes du plus beau fleuve au monde 